\title{
Risk factors of infection in patients with hematological malignancy
}

\author{
Tomoyuki Kawada ${ }^{1}$
}

Received: 19 March 2019 / Accepted: 15 April 2019 / Published online: 23 May 2019

(C) Springer-Verlag GmbH Germany, part of Springer Nature 2019

Dear Editor,

Brioli et al. conducted a retrospective study to identify risk factors of infections in 479 myeloma patients [1]. Infections were strongly associated with high disease burden, relapsed disease, and treatment with high-dose chemotherapy. Among them, varicella zoster (VZ) virus reactivations occurred late during treatment, which should be prevented to reduce lethal complication. I have two concerns about the study with special reference to varicella (herpes) zoster virus infection in patients with hematological malignancy.

First, Goenaga Vazquez et al. conducted a retrospective cohort study to evaluate risk factors of herpes zoster (HZ) incidence in 415 patients with lymphoma [2]. Adjusted relative risk (RR) (95\% confidence interval (CI)) was calculated by adopting Poisson regression analysis. During a median follow-up of 8.9 years, 46 patients of $\mathrm{HZ}$ were identified and adjusted RR (95\% CI) of highly immunosuppressive chemotherapy for $\mathrm{HZ}$ was 2.88 (1.47-5.623). Cho et al. also evaluated risk factors for herpes zoster in patients with nonHodgkin lymphoma [3]. After adjusting for the propensity score matching, odds ratios $(95 \% \mathrm{CI})$ of the addition of rituximab to conventional chemotherapy for the 1-year and 2-year incidence of $\mathrm{HZ}$ were 1.38 (1.05-1.81) and 1.37 (1.08-1.73), respectively. This means that combination chemotherapy with rituximab significantly increased the risk of $\mathrm{HZ}$ incidence, and the strong immunosuppression should be paid to $\mathrm{HZ} / \mathrm{VZ}$ infection.

Second, Liu et al. conducted a population-based matched-controlled prospective study to evaluate the risk of lymphoid malignancy before $\mathrm{HZ}$ infection by excluding subjects with duration from herpes zoster to diagnosis of malignancies less than 6 months [4]. By using Cox

Tomoyuki Kawada

kawada@nms.ac.jp

1 Department of Hygiene and Public Health, Nippon Medical School, 1-1-5 Sendagi, Bunkyo-Ku, Tokyo 113-8602, Japan proportional hazard regression analysis, adjusted hazard ratio $(95 \% \mathrm{CI})$ of $\mathrm{HZ}$ patients for developing lymphoid malignancies was 1.68 (1.35-2.42). Preceding HZ infection was an independent risk factor for subsequent lymphoid malignancies, and causal relationship between HZ infection and lymphoid malignancies should also be considered for the risk assessment of lymphoma.

\section{Compliance with ethical standards}

Conflict of interest The author declares that he has no conflict of interest.

Ethical approval and informed consent This article contains no studies with human participants or animals performed by the author. Informed consent is not needed.

\section{References}

1. Brioli A, Klaus M, Sayer H, Scholl S, Ernst T, Hilgendorf I, Scherag A, Yomade O, Schilling K, Hochhaus A, Mügge LO, von LilienfeldToal M (2019) The risk of infections in multiple myeloma before and after the advent of novel agents: a 12-year survey. Ann Hematol 98: 713-722. https://doi.org/10.1007/s00277-019-03621-1

2. Goenaga Vázquez Y, Cabanillas F, Concepción JR, Díaz Miranda OL (2019) Incidence and risk factors for developing herpes zoster among a cohort of patients diagnosed with lymphoma at a community cancer center. Clin Lymphoma Myeloma Leuk 19:e153-e158. https://doi.org/10.1016/j.clml.2018.12.001

3. Cho SF, Wu WH, Yang YH, Liu YC, Hsiao HH, Chang CS (2015) Longitudinal risk of herpes zoster in patients with non-Hodgkin lymphoma receiving chemotherapy: a nationwide population-based study. Sci Rep 5:14008. https://doi.org/10.1038/srep14008

4. Liu YC, Yang YH, Hsiao HH, Yang WC, Liu TC, Chang CS, Yang MY, Lin PM, Hsu JF, Chang PY, Lin SF (2012) Herpes zoster is associated with an increased risk of subsequent lymphoid malignancies - a nationwide population-based matched-control study in Taiwan. BMC Cancer 12:503. https://doi.org/10.1186/1471-2407$12-503$

Publisher's note Springer Nature remains neutral with regard to jurisdictional claims in published maps and institutional affiliations. 